Journal of Engineering and Applied Sciences 15 (6): 1573-1578, 2020

ISSN: 1816-949X

(C) Medwell Journals, 2020

\title{
A Stochastic Approach to Determine Seroconversion Time under Alertness using Erlang Truncated Exponential Distribution
}

\author{
R. Kannan and G. Parthasarathi \\ Department of Statistics, Annamalai University, Tamil Nadu, India
}

\begin{abstract}
In the study of HIV infection and its consequences the seroconversion of infected is a vital event. The HIV virus is commonly transmitted via. unprotected sexual activity, blood transfusions, hypodermic needles and from mother to child.The concept of alertness is gaining the greater important now a days in view of both prevention and delaying the process of seroconversion.
\end{abstract}

Key words: Acquired immune deficiency syndrome, human immune deficiency virus, seroconversion, antigenic diversity threshold and alertness, exponential distribution, simulated data

\section{INTRODUCTION}

The spread of Human Immune deficiency Virus (HIV) and consequent Acquired Immune Deficiency Syndrome (AIDS) has created a pandemic situation in many countries of the world. The HIV is a lentivirus organism that attacks the power of immunity in the human body. It is disheartening to note that there is no proper and definite cure for this infection till this day all the efforts of the scientist in inventing a medicine for this is still in process.

One of the models of transmission of HIV from the infected to any other person is by sexual contacts. The transmission of HIV from the infected to the other on successive contacts leads to the contribution of antigenic diversity of the antigen which in turn increases the survival of the antigens. The cumulative contribution to the antigenic diversity of the invading antigen in successive contacts if exceeds a particular level called antigenic diversity threshold then the human immune system is unable to fight against the antigens. The determination of the intensity of antigenic of the intensity of antigenic diversity has been studied by several researchers. Nowak and May (1991) have studied the antigenic diversity. Jewell and Shiboski (1990) have discussed the infectivity of HIV. Kannan et al. (2007) have used a mathematical model to determine the expected time to seroconversion Stilianakis et al. (1994) have discussed on the antigenic diversity threshold model for AIDS.

In the model, it is consider that a person takes some precautionary measures to avoid the transmission of HIV and this is called the alertness. However, if a person fails to adopt such preventive measure in other words if the person is in alert then the HIV gets transmitted. So, the model observed here is under the assumption that the transmission of HIV is possible only during the contacts without alertness. A stochastic model for HIV transmission under alertness under the assumption that threshold level of antigenic diversity is a random variable which follows a gamma distribution and exponential geometric distribution has been discussed by Kannan et al. (2007), Kannan and Chandrasekar (2015). The expected time to seroconversion is estimated using transmission probability with threshold of an Erlang truncated exponential distribution. Numerical illustration is also providing.

\section{MATERIALS AND METHODS}

The model: In this model, a situation where a person adopts the preventive strategy with a probability ' $\mathrm{p}$ ' during a sexual contact is considered. It is logical to assume that the transmission of HIV is possible only during a contact in which a person is inalert. At the same time HIV transmission is not a sure event according to medical finding. So, it is assumed that HIV transmission is possible during the sexual contact. Hence, one can visualize the following possibilities:

- A person is alert with probability 'p' and during the contact invasion of HIV does not take place

- A person is inalert with probability ' $q$ ' and transmission occurs with probability $\beta$

- A person is inalert with probability ' $\mathrm{q}$ ' and transmission does not occurs and the probability of this event is $(1-\beta)$

\section{Assumptions of the model:}

- Sexual contact is the only source of HIV transmission

- During any contact in which a person is unalert the transmission of HIV is a sure event

- An individual is exposed to damage process acting on the immune system and damage is assumed to be linear and cumulative 
- Damages occur if a partner is unalert

- If the total damage caused exceeds a particular level called the threshold $\mathrm{Y}$ which itself is a random variable, the seroconversion occurs and person is recognized as infected

- In any single contact a person is alert with probability ' $\mathrm{p}$ ' and unalert with probability ' $\mathrm{q}$ ', so that, $\mathrm{p}+\mathrm{q}=1$

\section{RESULTS AND DISCUSSION}

It can be shown that:

$$
P\left[\sum_{i=1}^{k} X_{i}<Y\right]=\int_{0}^{\infty} g_{k}(x) \bar{H}(x) d x
$$

Where:

$$
\overline{\mathrm{H}}(\mathrm{x})=1-\mathrm{H}(\mathrm{x})
$$

This gives the probability that a ' $k$ ' contact, the increases in antigenic diversity does not cross the antigenic diversity threshold level Y. Let $\mathrm{Y} \sim$ Erlang truncated exponential $(\lambda, \theta)$ :

$$
\begin{gathered}
\bar{H}(y)=e^{-\theta x\left(1-e^{-\lambda}\right)} \\
P\left(\sum_{t=1}^{k} X_{t}<Y\right)=\int_{0}^{\infty} g_{k}(x) \bar{H}(x) d x= \\
\int_{0}^{\infty} g_{k}(x) e^{-\theta x\left(1-e^{-\lambda}\right)} d x=\left[g^{*}\left(\theta\left(1-e^{-\lambda}\right)\right)\right]^{k}
\end{gathered}
$$

We define the survival function as $\mathrm{S}(\mathrm{t})$ :

$$
\mathrm{S}(\mathrm{t})=\mathrm{P}[\mathrm{T}>\mathrm{t}]
$$

$=\sum_{\mathrm{k}=0}^{\infty} \operatorname{Pr}\{$ there are exactly $\mathrm{k}$ constant in $(0, \mathrm{t}]\} * \operatorname{Pr}\{$ the cumulative total of antigenic diversity $<\mathrm{Y}\}$ :

$$
\begin{gathered}
S(t)=\sum_{K=0}^{\infty} V_{k}(t) P\left[\sum_{i=1}^{k} X_{i}<Y\right]= \\
\sum_{K=0}^{\infty}\left[F_{k}(t)-F_{k+1}(t)\right]\left[g *\left(\theta\left(1-e^{-\lambda}\right)\right)\right]^{k} \\
L(t)=1-S(t) \\
L(t)=1-\sum_{K=0}^{\infty}\left[F_{k}(t)-F_{k+1}(t)\right]\left[g^{*}\left(\theta\left(1-e^{-\lambda}\right)\right)\right]^{k} \\
L(t)=\left\{\left[1-g^{*}\left(\theta\left(1-e^{-\lambda}\right)\right)\right] \sum_{k=1}^{\infty} F_{k}(t)\left[1-g^{*}\left(\theta\left(1-e^{-\lambda}\right)\right)\right]\right\}^{k-1}
\end{gathered}
$$

Using Laplace Steiltjie's transform and $\mathrm{F}_{0}(\mathrm{t})=1$ then it can be shown that:

$$
\mathrm{I}^{*}(\mathrm{~s})=\frac{\left[1-\mathrm{g}^{*}\left(\theta\left(1-\mathrm{e}^{-\lambda}\right)\right)\right] \mathrm{f}^{*}(\mathrm{~s})}{\left[1-\mathrm{g}^{*}\left(\theta\left(1-\mathrm{e}^{-\lambda}\right)\right)\right] \mathrm{f}^{*}(\mathrm{~s})}(\text { on simplification })
$$

The cdf of $\mathrm{z}$ is given by:

$$
F^{*}(z)=\left[q \beta \sum_{n=0}^{\infty}[p+q(1-\beta)]^{n} G_{n+1}(z)\right]^{n}
$$

The laplace transformation of $\mathrm{F}(\mathrm{z})$ is:

$$
F^{*}(s)=\int_{0}^{\infty} e^{-s t} d F(z)
$$

$$
\begin{aligned}
& \mathrm{F}^{*}(\mathrm{z})=\left[\mathrm{q} \beta \mathrm{G}^{*}(\mathrm{~s}) \sum_{\mathrm{n}=0}^{\infty}[\mathrm{p}+\mathrm{q}(1-\beta)] \mathrm{G}^{*}(\mathrm{~s})\right]^{\mathrm{n}} \\
& \mathrm{F}^{*}(\mathrm{z})=\frac{\mathrm{q} \beta \mathrm{G}^{*}(\mathrm{~s})}{1-[\mathrm{p}+\mathrm{q}(1-\beta)] \mathrm{G}^{*}(\mathrm{~s})} \\
& \mathrm{f}^{*}(\mathrm{~s})=\frac{\mathrm{q} \beta \mathrm{g}^{*}(\mathrm{~s})}{1-[\mathrm{p}+\mathrm{q}(1-\beta)] \mathrm{g}^{*}(\mathrm{~s})}
\end{aligned}
$$

Assuming that $g(.) \sim \exp (c)$ then:

Now:

$$
\mathrm{g}^{*}(\mathrm{~s})=\frac{\mathrm{c}}{\mathrm{c}+\mathrm{s}}, \mathrm{g}^{\prime \prime \prime}(0)=-\frac{1}{\mathrm{c}} \text { and }^{* \prime \prime}(0)=\frac{2}{\mathrm{c}^{2}}
$$

$$
f^{* \prime}(s)=\frac{\left[1-[p+q(1-\beta)] g^{*}(s)\right] q \beta g^{* \prime}(s)[p+q(1-\beta)] g^{* \prime}(s)}{\left[1-[p+q(1-\beta)] g^{*}(s)\right]^{2}}
$$

At $\mathrm{s}=0$ :

$$
\mathrm{f}^{* *}(0)=-\frac{1}{\mathrm{cq} \beta}
$$

Then:

$$
\begin{aligned}
& f^{* \prime \prime}(s)=\frac{d^{2} f^{*}(s)}{d s^{2}} \\
& {\left[1-[\mathrm{p}+\mathrm{q}(1-\beta)] \mathrm{g}^{*}(\mathrm{~s})\right]^{2}\left\{\begin{array}{l}
{\left[1-[\mathrm{p}+\mathrm{q}(1-\beta)] \mathrm{g}^{*}(\mathrm{~s})\right] \mathrm{q} \beta \mathrm{g}^{* \prime}(\mathrm{s})-} \\
\mathrm{q} \beta \mathrm{g}^{* \prime}(\mathrm{s})[\mathrm{p}+\mathrm{q}(1-\beta)] \mathrm{g}^{* \prime}(\mathrm{s})+ \\
\mathrm{q} \beta \mathrm{g}^{*}(\mathrm{~s})[\mathrm{p}+\mathrm{q}(1-\beta)] \mathrm{g}^{* \prime \prime}(\mathrm{s}) \\
{[\mathrm{p}+\mathrm{q}(1-\beta)] \mathrm{g}^{\prime \prime \prime}(\mathrm{s}) \mathrm{q} \beta \mathrm{g}^{* \prime \prime}(\mathrm{s})}
\end{array}\right\}+} \\
& {\left[1-[p+q(1-\beta)] g^{*}(s) q \beta g^{* \prime}(s)+q \beta g^{*}(s)\right.} \\
& \mathrm{f}^{* \prime \prime}(\mathrm{s})=\frac{\left[\mathrm{p}+\mathrm{q}(1-\beta) \mathrm{g}^{* \prime}(\mathrm{s})\left\{2\left[1-[\mathrm{p}+\mathrm{q}(1-\beta)] \mathrm{g}^{*}(\mathrm{~s})\right]\right\}\right.}{\left[1-[\mathrm{p}+\mathrm{q}(1-\beta)] \mathrm{g}^{*}(\mathrm{~s})\right]^{4}}
\end{aligned}
$$

At $\mathrm{s}=0$ : 


$$
f^{* * \prime}(0)=\frac{g^{* \prime \prime}(0)}{q \beta}+\frac{2(1-q \beta)\left[g^{* \prime \prime}(0)\right]^{2}}{[q \beta]^{2}}
$$

When using:

$$
g^{\prime \prime \prime}(0)=-\frac{1}{c} \text { and } g^{* \prime \prime}(0)=\frac{2}{c^{2}}
$$

Then:

$$
f^{* * \prime}(0)=\frac{2}{c^{2} q^{2} \beta^{2}}
$$

Now to find $E$ (T):

$$
\begin{gathered}
E(T)=\left\{-\frac{d l^{*}(s)}{d s}\right\}_{s=0} \\
E(T)=\left\{\frac{\left[1-\mathrm{g}^{*}\left(\theta\left(1-\mathrm{e}^{-\lambda}\right)\right] \mathrm{f}^{* *}(\mathrm{~s})\right.}{\left[1-\mathrm{g}^{*}\left(\theta\left(1-\mathrm{e}^{-\lambda}\right)\right) \mathrm{f}^{*}(\mathrm{~s})\right]^{2}}\right\}_{\mathrm{s}=0}
\end{gathered}
$$

Using (5.3) and assuming g (.) exp ( $\mu$ ), we get:

$$
E(T)=\frac{(\mu+\theta)\left(\mu+\theta \mathrm{e}^{-\lambda}\right)}{\operatorname{cq} \beta\left(\mu^{2}+2 \mu \theta+\theta^{2} \mathrm{e}^{-\lambda}\right)}
$$

To find $\mathrm{E}\left(\mathrm{T}^{2}\right)$ :

$$
E\left(T^{2}\right)=\left\{\frac{d^{2} I^{*}(s)}{d s^{2}}\right\}_{s=0}
$$

Now:

$$
\begin{aligned}
& \frac{\mathrm{d}^{2} \mathrm{I}^{*}(\mathrm{~s})}{\mathrm{ds} \mathrm{s}^{2}}=\left\{\left[1-\left(\mathrm{g}^{*}\left(\theta\left(1-\mathrm{e}^{-\lambda}\right)\right)\right)\right]\left[\begin{array}{l}
{\left[1-\left(\mathrm{g}^{*}\left(\theta\left(1-\mathrm{e}^{-\lambda}\right)\right) \mathrm{f}^{* *}(\mathrm{~s})-\right.\right.} \\
2 \mathrm{~g}^{*}\left(\theta\left(1-\mathrm{e}^{-\lambda}\right)\left[\mathrm{f}^{* \prime}(\mathrm{s})\right]^{2}\right.
\end{array}\right\}_{\mathrm{s}=0}^{\left[1-\mathrm{g}^{*}\left(\theta\left(1-\mathrm{e}^{-\lambda}\right)\right) \mathrm{f}^{*}(\mathrm{~s})\right]^{3}}\right. \\
& \frac{\mathrm{d}^{2} \mathrm{I}^{*}(\mathrm{~s})}{\mathrm{ds}^{2}}=\left[1-\left(\mathrm{g}^{*}\left(\theta\left(1-\mathrm{e}^{-\lambda}\right)\right)\right] \frac{\begin{array}{l}
1-\left(\left(\mathrm{g}^{*} \theta\left(1-\mathrm{e}^{-\lambda}\right)\right) \mathrm{f}^{* *}(0)-\right. \\
2 \mathrm{~g}^{*}\left(\theta\left(1-\mathrm{e}^{-\lambda}\right)\left[\mathrm{f}^{* *}(0)\right]^{2}\right.
\end{array}}{\left[1-\mathrm{g}^{*}\left(\theta\left(1-\mathrm{e}^{-\lambda}\right)\right) \mathrm{f}^{*}(0)\right]^{3}}\right.
\end{aligned}
$$

Using (5.3) and (5.4), we get:

$$
\left\{\frac{\mathrm{d}^{2} \mathrm{l}^{*}(\mathrm{~s})}{\mathrm{ds}^{2}}\right\}_{\mathrm{s}=0}=\frac{2}{\mathrm{c}^{2} \mathrm{q}^{2} \beta^{2}\left(1-\mathrm{g}^{*}\left(\theta\left(1-\mathrm{e}^{-\lambda}\right)\right)\right)^{2}}
$$

Since, g (.) exp ( $\mu$ ) then:

$$
\begin{aligned}
& \left\{\frac{\mathrm{d}^{2} \mathrm{l}^{*}(\mathrm{~s})}{\mathrm{ds}^{2}}\right\}_{\mathrm{s}=0}=\frac{2(\mu+\theta)^{2}\left(\mu+\theta \mathrm{e}^{-\lambda}\right)^{2}}{\mathrm{c}^{2} \mathrm{q}^{2} \beta^{2}\left(\mu^{2}+2 \mu \theta+\theta^{2} \mathrm{e}^{-\lambda}\right)^{2}} \\
& \Rightarrow \mathrm{E}\left(\mathrm{T}^{2}\right)=\frac{2(\mu+\theta)^{2}\left(\mu+\theta \mathrm{e}^{-\lambda}\right)^{2}}{\mathrm{c}^{2} \mathrm{q}^{2} \beta^{2}\left(\mu^{2}+2 \mu \theta+\theta^{2} \mathrm{e}^{-\lambda}\right)^{2}}
\end{aligned}
$$

To find the variance:

$$
\begin{gathered}
\mathrm{V}(\mathrm{T})=\mathrm{E}\left(\mathrm{T}^{2}\right)-[\mathrm{E}(\mathrm{T})]^{2} \\
\mathrm{~V}(\mathrm{~T})=\frac{2(\mu+\theta)^{2}\left(\mu+\theta \mathrm{e}^{-\lambda}\right)^{2}}{\mathrm{c}^{2} \mathrm{q}^{2} \beta^{2}\left(\mu^{2}+2 \mu \theta+\theta^{2} \mathrm{e}^{-\lambda}\right)^{2}}-\left[\frac{(\mu+\theta)\left(\mu+\theta \mathrm{e}^{-\lambda}\right)}{c \mathrm{cq} \beta\left(\mu^{2}+2 \mu \theta+\theta^{2} \mathrm{e}^{-\lambda}\right)}\right]^{2} \\
\mathrm{~V}(\mathrm{~T})=\frac{(\mu+\theta)^{2}\left(\mu+\theta \mathrm{e}^{-\lambda}\right)^{2}}{\mathrm{c}^{2} \mathrm{q}^{2} \beta^{2}\left(\mu^{2}+2 \mu \theta+\theta^{2} \mathrm{e}^{-\lambda}\right)^{2}}
\end{gathered}
$$

Special case: When there is no alertness then $\mathrm{q}=1$, $\beta=1$, so:

$$
\mu_{\mathrm{t}}=\frac{(\mu+\theta)\left(\mu+\theta \mathrm{e}^{-\lambda}\right)}{\left(\mu^{2}+2 \mu \theta+\theta^{2} \mathrm{e}^{-\lambda}\right)}
$$

In case of alertness:

$$
\mu_{\mathrm{ta}}=\frac{(\mu+\theta)\left(\mu+\theta \mathrm{e}^{-\lambda}\right)}{\operatorname{cq} \beta\left(\mu^{2}+2 \mu \theta+\theta^{2} \mathrm{e}^{-\lambda}\right)}
$$

Therefore, $\mu_{\mathrm{ta}}>\mu_{\mathrm{t}}$ and this implies that mean time to seroconversion is large in case of alertness, this is inversely proportional to the probability of non-alertness ' $q$ ' which is an interesting result:

$$
\sigma_{\mathrm{ta}}^{2}=\frac{2(\mu+\theta)^{2}\left(\mu+\theta \mathrm{e}^{-\lambda}\right)^{2}}{\mathrm{c}^{2} \mathrm{q}^{2} \beta^{2}\left(\mu^{2}+2 \mu \theta+\theta^{2} \mathrm{e}^{-\lambda}\right)^{2}}
$$

When there is no alertness $q=1, \beta=1$ then the variance is same as the results obtained by Kannan and Parthasarathi (2017).

Numerical illustrations: Table 1, shows the values of expected time to seroconversion corresponding to the variation in $\mathrm{c}$, the parameter of the distribution of inter-arrival time when $q, \mu, \theta, \lambda$ are kept fixed. As c increases which means the average of inter-arrival time become smaller, so, there is a corresponding decrease in expected time to seroconversion and also its variance as shown in Fig. 1. 
J. Eng. Applied Sci., 15 (6): 1573-1578, 2020

Table 1: Shows the values of expected time to seroconversion

\begin{tabular}{lrr}
\hline $\mathrm{C}$ & $\mathrm{E}(\mathrm{T})$ & $\mathrm{V}(\mathrm{T})$ \\
\hline 1 & 17.8180 & 317.4817 \\
2 & 8.9090 & 79.3704 \\
3 & 5.9393 & 35.2757 \\
4 & 4.4545 & 19.8426 \\
5 & 3.5636 & 12.6993 \\
6 & 2.9697 & 8.8189 \\
7 & 2.5454 & 6.4792 \\
8 & 2.2273 & 4.9607 \\
9 & 1.9798 & 3.9195 \\
10 & 1.7818 & 3.1748 \\
\hline$\mu=0.2, \theta=0.2, \lambda=0.5, \mathrm{q}=0.5, \beta=0.1$ &
\end{tabular}

Table 2: Contribution of the antigenic diversity increases

\begin{tabular}{lcr}
\hline$\mu$ & $\mathrm{E}(\mathrm{T})$ & $\mathrm{V}(\mathrm{T})$ \\
\hline 0.1 & 0.8940 & 0.7993 \\
0.2 & 0.8909 & 0.7937 \\
0.3 & 0.8992 & 0.8086 \\
0.4 & 0.9086 & 0.8255 \\
0.5 & 0.9170 & 0.8410 \\
0.6 & 0.9244 & 0.8544 \\
0.7 & 0.9306 & 0.8661 \\
0.8 & 0.9360 & 0.8762 \\
0.9 & 0.9407 & 0.8849 \\
1 & 0.9447 & 0.8925 \\
\hline $\mathrm{C}=2, \theta=0.2, \lambda=0.5, \mathrm{q}=0.5, \beta=0.1$ &
\end{tabular}

Table 3: The variation in $\mathrm{E}(\mathrm{T})$ and $\mathrm{V}(\mathrm{T})$ consequent changes in

\begin{tabular}{lcc}
\multicolumn{2}{c}{ parameter $\theta$} & \\
\hline$\theta$ & $\mathrm{E}(\mathrm{T})$ & $\mathrm{V}(\mathrm{T})$ \\
\hline 0.01 & 8.184497 & 66.98599 \\
0.02 & 8.061465 & 64.98722 \\
0.03 & 7.958928 & 63.34453 \\
0.04 & 7.872897 & 61.98250 \\
0.05 & 7.800319 & 60.84497 \\
0.06 & 7.738821 & 59.88935 \\
0.07 & 7.686532 & 59.08278 \\
0.08 & 7.641961 & 58.39957 \\
0.09 & 7.603902 & 57.81933 \\
0.1 & 7.571374 & 57.32571 \\
\hline
\end{tabular}

$\mathrm{C}=2, \mu=0.2, \lambda=0.5, \mathrm{q}=0.5, \beta=0.1$

As the value of $\mu$ which is parameter of the random variable $X_{i}$ denoting to the contribution of the antigenic diversity increases then it is seen that expected time to seroconversion and variance of seroconversion increases as indicated in Table 2 and Fig. 2.

In Table 3 and Fig. 3 the variation in $\mathrm{E}(\mathrm{T})$ and $\mathrm{V}(\mathrm{T})$ consequent changes in parameter $\theta$ is noted. As the parameter of the threshold distribution $\theta$ increases the mean time to seroconversion as well as variance time to seroconversion are decreased.

In Table 4 as the value of the threshold parameter $\lambda$ increases then the expected time to seroconversion and variance of seroconversion are decreases as shown in Fig. 4.

From Table 5, we observe that if the inalert probability ' $q$ ' increases, the contribution of antigenic diversity in successive contact will be more and hence, there is a decrease in mean time to seroconversion and also its variance as shown in Fig. 5.
Table 4: Value of the threshold parameter $\lambda$ increases then the expected

\begin{tabular}{lcc}
\cline { 2 - 2 }$\lambda$ & time to & \\
\hline 0.1 & $\mathrm{E}(\mathrm{T})$ & $\mathrm{V}(\mathrm{T})$ \\
0.2 & 9.7563 & 95.1853 \\
0.3 & 9.5253 & 90.7316 \\
0.4 & 9.3072 & 86.6231 \\
0.5 & 9.1018 & 82.8422 \\
0.6 & 8.9090 & 79.3704 \\
0.7 & 8.7286 & 76.1888 \\
0.8 & 8.5603 & 73.2782 \\
0.9 & 8.4035 & 70.6195 \\
1 & 8.2580 & 68.1943 \\
$\mathrm{C}=2, \mu=0.2, \theta=0.2, \mathrm{q}=0.5, \beta=0.1$ & 65.9846 \\
\hline
\end{tabular}

Table 5: Inalert probability ' $q$ ' increases, the contribution of antigenic diversity in successive contact will be more

\begin{tabular}{lcr}
\hline $\mathrm{q}$ & $\mathrm{E}(\mathrm{T})$ & $\mathrm{V}(\mathrm{T})$ \\
\hline 0.1 & 44.5450 & 1984.2610 \\
0.2 & 22.2725 & 496.0652 \\
0.3 & 14.8483 & 220.4734 \\
0.4 & 11.1363 & 124.0163 \\
0.5 & 8.9090 & 79.3704 \\
0.6 & 7.4242 & 55.1184 \\
0.7 & 6.3636 & 40.4951 \\
0.8 & 5.5681 & 31.0041 \\
0.9 & 4.9494 & 24.4970 \\
1 & 4.4545 & 19.8426 \\
\hline $\mathrm{C}=2, \mu=0.2, \lambda=0.5, \theta=0.2, \beta=0.1$ &
\end{tabular}

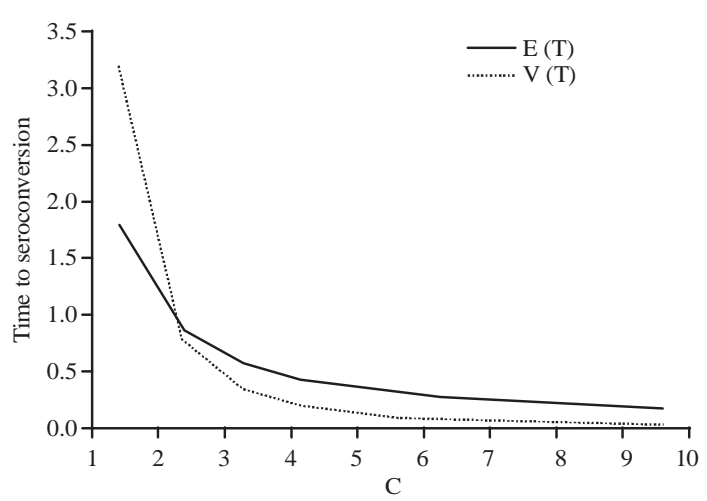

Fig. 1: Corresponding decrease in expected time to seroconversion and also its variance

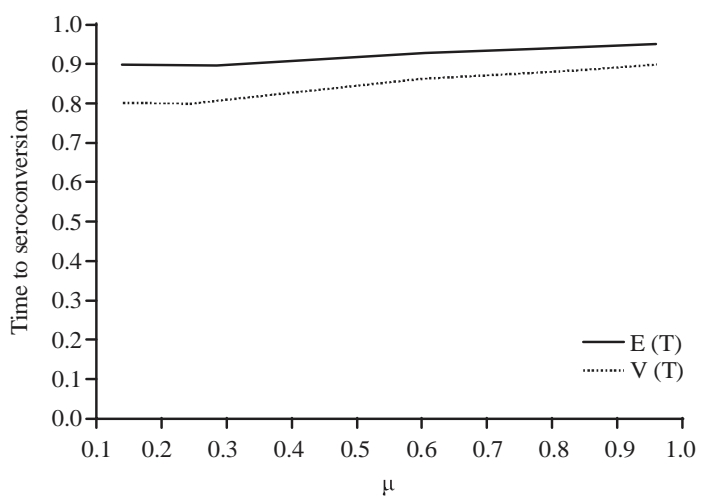

Fig. 2: Expected time to seroconversion and variance of seroconversion increases 


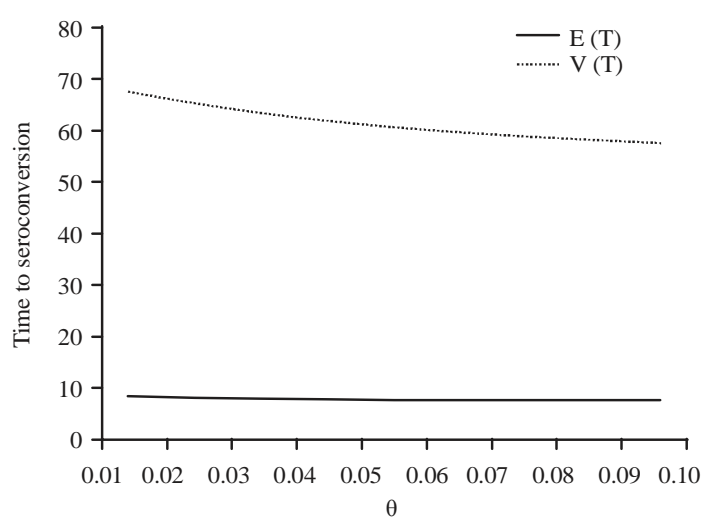

Fig. 3: Parameter of the threshold distribution $\theta$ increases the mean time to seroconversion as well as variance time to seroconversion

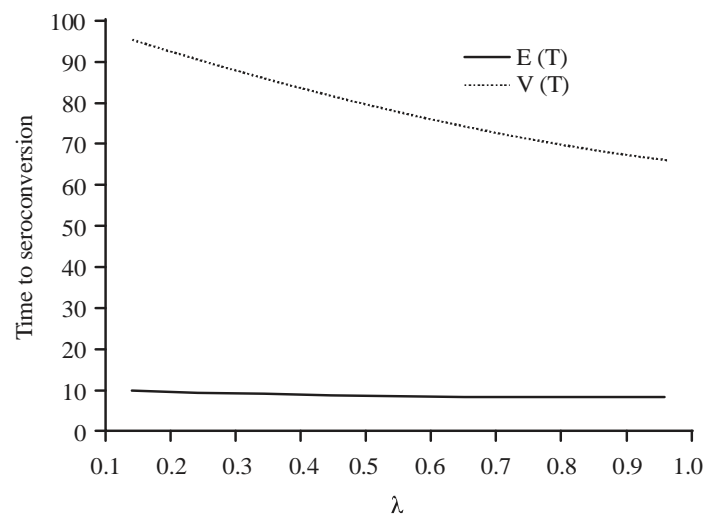

Fig. 4: Variance of seroconversion are decreases

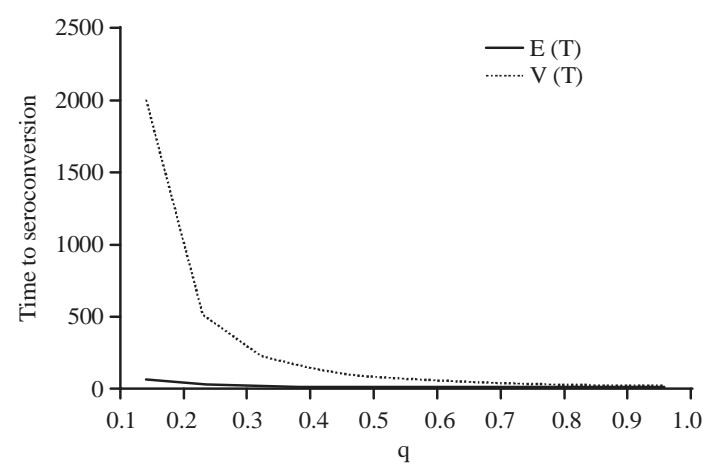

Fig. 5: Decrease in mean time to seroconversion and also its variance

From Table 6, we observe that if the transmission probability ' $\beta$ ' increases, the contribution of antigenic diversity in successive contact will be more and hence, there is a decrease in mean time to seroconversion and also its variance as shown in Fig. 6.

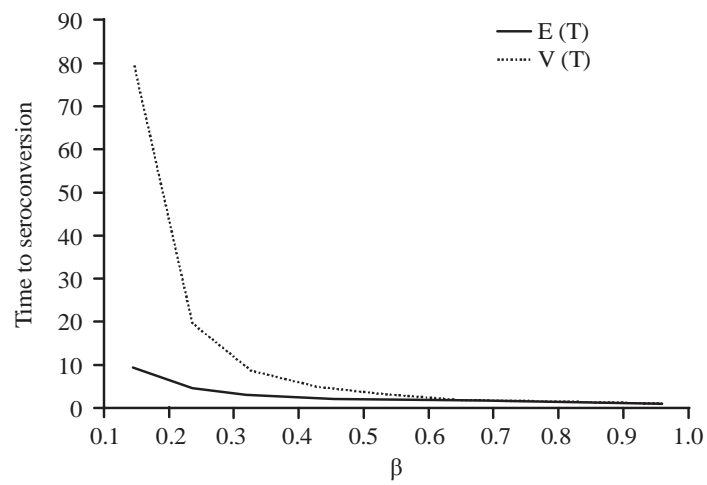

Fig. 6: Decrease in mean time to seroconversion and also its variance

Table 6: Transmission probability ' $\beta$ ' increases, the contribution of antigenic diversity in successive contact will be more

\begin{tabular}{lcr}
\hline$\beta$ & $\mathrm{E}(\mathrm{T})$ & $\mathrm{V}(\mathrm{T})$ \\
\hline 0.1 & 8.9090 & 79.3704 \\
0.2 & 4.4545 & 19.8426 \\
0.3 & 2.9697 & 8.8189 \\
0.4 & 2.2273 & 4.9607 \\
0.5 & 1.7818 & 3.1748 \\
0.6 & 1.4848 & 2.2047 \\
0.7 & 1.2727 & 1.6198 \\
0.8 & 1.1136 & 1.2402 \\
0.9 & 0.9899 & 0.9799 \\
1 & 0.8909 & 0.7937 \\
\hline $\mathrm{C}=2, \mu=0.2 \lambda=0.5, \theta=0.2, \mathrm{q}=0.5$ &
\end{tabular}

\section{CONCLUSION}

In this study using the concept of alertness a stochastic model for seroconversion time are derived under the assumption that the threshold level of antigenic diversity follows an Erlang truncated exponential distribution. Numerical illustration is provided using simulated data.

\section{NOTATIONS}

$X_{i} \quad$ : A random variable denoting the increase in the antigenic diversity arising due to the HIV transmitted during the ith contact $\mathrm{X}_{1}, \mathrm{X}_{2}, \ldots, \mathrm{X}_{\mathrm{k}}$ are continuous iid. random variables, with pdf $g$ (.) and cdf G (.)

Y : A random variable representing antigenic diversity threshold and follows erlang truncated exponential distribution with parameters $\theta$ and $\lambda$, the pdf being $h($.$) and \operatorname{cdf} \mathrm{H}($.

$\mathrm{U}_{\mathrm{i}} \quad$ : A continuous random variable denoting the inter-arrival times between successive contacts with pdf $\mathrm{f}($.$) and cdf F($.

$g_{k}($.$) : The pdf of random variable \sum^{k} X_{i}$

$F_{k}($.$) : The kth convolution of F(.){ }_{i=1}$

$\mathrm{T}$ : A continuous random variable denoting the time of seroconversion with pdf $\mathrm{l}($.$) and \mathrm{cdf} \mathrm{L}($. 
$\mathrm{V}_{\mathrm{k}}(\mathrm{t})$ : The probability of exactly $\mathrm{k}$ contacts in $(\mathrm{o}, \mathrm{t}]$

$l^{*}(\mathrm{~s})$ : The Laplace Stieltje's transform of $l(\mathrm{t})$

$\mathrm{f}^{*}(\mathrm{~s})$ : The Laplace Stieltje's transform of $\mathrm{f}(\mathrm{t})$

\section{REFERENCES}

Jewell, N.P. and S.C. Shiboski, 1990. Statistical analysis of HIV infectivity based on partner studies. Biom., 46: 1133-1150.

Kannan, R. and G. Parthasarathi, 2017. A stochastic model for the estimation of time to seroconversion of HIV transmission using Erlang Truncated Exponentail distribution. Intl. J. Stat. Appl. Math., 2: 211-215.
Kannan, R. and K. Chandrasekar, 2015. A stochastic model for estimation of expected time to seroconversion of HIV infected using alertness. Intl. J. Math. Arch., 6: 16-22.

Kannan, R., K.A. Venkatachalam, R. Sathiyamoorthi and G. Malarvizhi, 2007. A stochastic model for HIV transmission under alertness. Biosci, Res. Bull., 23: 25-38.

Nowak, M.A. and R.M. May, 1991. Mathematical biology of HIV infections: Antigenic variation and diversity threshold. Math. Biosci., 106: 1-21.

Stilianakis, N.I., D. Schenzle and K. Dietz, 1994. On the antigenic diversity threshold model for AIDS. Math. Biosci., 121: 235-247. 